\title{
Drivers of passive leadership in wild songbirds: species-level differences and spatio-temporally dependent intraspecific effects
}

\author{
Samin Gokcekus ${ }^{1}$ (D) $\cdot$ Josh A. Firth ${ }^{1,2} \cdot$ Charlotte Regan $^{1} \cdot$ Ella F. Cole ${ }^{1} \cdot$ Koosje P. Lamers $^{1} \cdot$ Ben C. Sheldon ${ }^{1}$
}

Received: 16 June 2021 / Revised: 9 November 2021 / Accepted: 11 November 2021 / Published online: 3 December 2021

(c) The Author(s) 2021

\begin{abstract}
Collective behaviors are typical for many social species and can have fitness benefits for participating individuals. To maximize the benefits obtained from group living, individuals must coordinate their behaviors to some extent. What are the mechanisms that make certain individuals more likely to initiate collective behaviors, for example, by taking a risk to initially access a resource (i.e., to act as "leaders")? Here, we examine leading behavior in a natural population of great tits and blue tits. We use automated feeding stations to monitor the feeder visits of tagged individuals within mixed-species flocks, with a small cost (waiting $<2$ s) associated with the initial unlocking of the feeder. We find that great tits, males, and individuals with high activity levels were more likely to be leading in each of their feeder visits. Using a null model approach, we demonstrate that the effects of sex and activity on passive leading behavior can be explained by patterns of spatial and temporal occurrence. In other words, these effects can be explained by the times and locations of when individuals visit rather than the actual order of arrival. Hence, an analysis of the causes of leading behavior is needed to separate the effects of different processes. We highlight the importance of understanding the mechanisms behind leading behavior and discuss directions for future experimental work to gain a better understanding of the causes of leadership in natural populations.
\end{abstract}

\section{Significance statement}

Many species are social and engage in collective behaviors. To benefit from group actions, individuals need to fulfill different roles. Here, we examine leading behavior during feeding events; who feeds first when birds arrive at a resource? In mixedspecies flocks of passerines, great tits (the larger and more dominant species), males, and individuals with higher levels of activity lead more often than blue tits, females, and individuals with lower levels of activity. While the species effect remains even when we control for the locations and dates of individual feeder visits, the effects of sex and activity are dependent on when and where birds choose to feed.

Keywords Leading $\cdot$ Sociality $\cdot$ Leadership $\cdot$ RFID

\section{Introduction}

Many species are social, spending a majority of their time in the presence of others, especially when moving or acting in groups is beneficial (Couzin et al. 2002; Krause and Ruxton

Communicated by K. van Oers.

Samin Gokcekus

samingokcekus@gmail.com

1 Department of Zoology, Edward Grey Institute, University of Oxford, Oxford, UK

2 Merton College, University of Oxford, Oxford, UK
2002; Couzin and Krause 2003). Collective action can occur in day-to-day contexts, for example, when individuals come together to forage in pairs or groups, presumably to increase their feeding efficiency and avoid predators (Conradt and Roper 2003; Rands et al. 2003; McClure et al. 2011). How are collective actions initiated and carried out in different species and contexts?

Various lines of research suggest that in social or groupliving species, there are some individuals that are more likely to initiate behaviors (leaders), while there are others that are more likely to follow once behavior is initiated (followers; King and Cowlishaw 2009; King et al. 2009; King 2010). Patterns of leading and following can occur not only during coordinated collective movements but also during 
social encounters (King et al. 2009) and remain consistent over time (Kurvers et al. 2009). However, the terms leader and follower can be ambiguous if clear definitions are not used (Dumont et al. 2005; Pyritz et al. 2011). Leader may be used in the more intentional sense, where individuals actively, and sometimes explicitly, make their intentions known and attempt to recruit group members to follow their behaviors (King et al. 2008; King and Sueur 2011). However, leadership in animal groups is rarely shown to be "active" or with the intention of eliciting followers. In a more passive sense, leading can be characterized in terms of the order that a behavior is occurring in, as an emergent property of the particular make-up of the given group or population (Couzin and Krause 2003; King 2010; Lucon-Xiccato et al. 2019). Conceptualizing passive leaders as individuals that take on an initial cost to access a resource and are followed by others more often than they follow others themselves, as we do here, allows for a flexible and generalized investigation of leadership across a range of systems.

There are many possible ways to explain leading behavior, based on morphological, physiological, and behavioral characteristics (King et al. 2009). One explanation is that leadership is driven by motivation, where individuals that are most in need of a particular resource are most likely to initiate behaviors to retrieve them (Furrer et al. 2012; Öst and Jaatinen 2013; Hansen et al. 2016). This is sometimes referred to as the "leading according to need" hypothesis (Conradt et al. 2009; Sumpter 2009). Dominant individuals may also be more likely to lead group movement if they operate more autonomously or have more command over the group (Rands et al. 2006). This may be related to the link between energetic intake (motivation) and dominance, where more dominant individuals are also more in need of resources (Muller and Wrangham 2004; Sueur et al. 2013). Alternatively, it is possible that subordinates have reduced access to resources and are therefore hungrier, or more risk-averse, and may attempt to arrive at a resource first to increase their probability of retrieving food. More generally, dominant individuals may be more successful in fostering following behavior (King et al. 2008).

For individuals to take advantage of and maximize the benefits that come from collective actions, individuals within a group must be coordinated to some extent (King and Cowlishaw 2009). Coordination can be hard to achieve as group members may have conflicting interests that must be resolved, making way for the emergence of leaders. Studies of leadership aim not only to uncover the mechanisms behind collective actions but also to investigate how dyadic interactions at the individual level translate to group-level patterns (Strandburg-Peshkin et al. 2018). Understanding the dynamics of leading and following behavior is crucial to our understanding of how social groups emerge and are maintained in different species and settings (Tóth and
Griggio, 2011). Leaders and followers may experience different fitness consequences of group membership; for example, leaders may receive a larger share of resources but be at a higher risk of being predated, while followers may not receive as much but benefit from the resource discoveries of leaders (Beauchamp 2000).

Uncovering the details of leading and following behavior can also help to refine our understanding of other social phenomena, for example, cooperation. It may be the case that individuals that are "leaders" during migration or foraging contexts are also those that are most likely to initiate cooperative behaviors (King et al. 2009). On the other hand, it is possible that cooperation occurs within social groups such that leaders are "helped" by others in exchange for their leadership (Kern and Radford 2018). Dynamics of leading and following may also be a form of cooperation in themselves. In their study of captive Northern bald ibis (Geronticus eremita) leading and following in V-formation flight, Voelkl et al. (2015) found that individuals would change positions in order to match their own leading time to the current leader's (direct reciprocity). Furthermore, how much an individual could benefit from being a follower was strongly correlated with how long they were the leader.

Foraging behavior and efficiency have direct consequences for fitness (Clark and Mangel 1986; Stephens et al. 2007), can vary widely both within and among groups (Milligan et al. 2017), and may influence social structure and dynamics (Methion and Díaz López 2020). Previous studies have explored leading behavior during foraging in birds in terms of moving from one patch of resources to another. In an early study, Beauchamp (2000) looked at the order of arrival of size- and food deprivation-matched pairs of zebra finches (Taenopygia guttata) to reach a foraging patch and found that the same individual was consistently arriving first. After additionally looking at their solitary activity and exploration levels in a novel environment, this research suggests that leadership is dependent most on activity and exploration levels, rather than dominance or motivation. However, it could be argued that individuals with higher levels of activity have higher energetic needs (Réale et al. 2010).

In their study on leading and following in rock sparrows (Petronia petronia), Tóth and Griggio (2011) found that individuals with a larger breast patch, a sexually selected trait, were more likely to be leaders regardless of sex or body condition. Because the breast patch is related to the ingestion of carotenoid-rich food (and condition dependent), they suggest that following these individuals may lead to more efficient foraging. Alternatively, it is possible that those individuals with larger breast patches are more in need of resources (particularly carotenoidrich ones) and are more likely to initiate foraging trips. Larger breast patches in this species are also indicative 
of dominance in terms of the ability to acquire territories and access to food resources (Griggio et al. 2007).

Understanding the relative contributions of spatiotemporal and individually driven mechanisms is a central aim of behavioral ecology because of the consequences for phenotypic selection (Kasumovic et al. 2008; Farine et al. 2015; Kay et al. 2017). Further work is necessary to gain more insight into the relative roles of different ecological drivers in causing leading behavior. What are the mechanisms behind various predictors of leadership? Are leader-follower dynamics maintained by the same mechanisms in different contexts, populations, and species? It may be that some classes of individuals are more likely to be leaders than others, but it is not always clear why this is the case; some effects may be dependent on spatial (where individuals are present) or temporal (when individuals are present) mechanisms. Furthermore, it is possible that certain individuals prefer to feed in particular locations because they are more (or less) likely to be leaders there.

Here, we study the individual feeder visits of birds once they arrive at a resource (as opposed to collective movement between areas). We explore patterns of passive leadership in mixed-species foraging flocks of passerine birds in order to uncover the factors (age, sex, species, activity level) that influence this behavior. In the winter, great tits and blue tits forage in mixed-species flocks that exhibit fission-fusion dynamics (Farine et al. 2012). As described by Hinde (1952), mixed-species flocks of tits often move in "integrated movements," arriving at a resource in a flock together and subsequently commencing feeding. Here, we use an experimental manipulation of feeder access to investigate the factors that predict whether individuals are leading or not at the scale of individual feeder visits. We define leaders as individuals that initially arrive and unlock a feeder, taking on the time "cost" (that comes with a higher chance of interference or risk) of waiting for feeders to open and also take any costs of being the first individual to approach and use the feeder, while those who feed from feeders that have already been unlocked are not; and leaders are individuals that are followed by others more than they follow others themselves. Based on the assumption that motivation and dominance are associated with higher rates of leading behavior, we predicted that great tits, males, adults, and individuals with higher levels of activity would be more likely to be engaged in leading behaviors. We additionally compare our results with specific null models, which directly incorporate consideration of patterns of non-independence within the data, and we use these to tease apart the influence of spatial and temporal drivers on these effects.

\section{Material and methods}

\section{Study system}

This work took place within a larger study on the social ecology of wild birds, conducted in Wytham Woods, Oxford, UK, on the long-term study population of great tits (Parus major), blue tits (Cyanistes caeruleus), marsh tits (Poecile palustris), coal tits (Periparus ater), and European nuthatches (Sitta europaea). Birds are marked with unique BTO (British Truth for Ornithology) metal leg rings and aged (juvenile if they were born in the most recent breeding season) and sexed during the breeding season at nest boxes or during the winter with mist netting. Captured birds are also fitted with a plastic leg ring housing a PIT (passive integrated transponder) tag that can be detected automatically when in the range of an RFID (radio frequency identification) antenna. It is estimated that more than $90 \%$ of the resident population is tagged (Aplin et al. 2013). In this system, sunflower seed feeding stations with RFID antennae (Dorset ID, Aalten, The Netherlands) are used to generate time (in seconds), date, and location stamped records of each individual's feeder visits. Mixed-species tit flocks feed on patches of resources that are scattered across the environment, and competition for food is most intense in mid-winter (Gibb 1954). Due to the relatively low number of individual coal tits, marsh tits, and nuthatches, we restricted our analyses to great tits and blue tits, the numerically dominant species within this system. However, data on individuals of other species were only removed after the labeling of intervisit intervals and leading-following events ("Determining leading and following behavior" section), in order to retain information about the true order of visits and whether they were a "following" event.

\section{Feeder sites}

The current study was conducted between November 2016 and January 2017 in the southernmost part of Wytham Woods (Bean Wood; 51 45' 28.8" N, $1^{\circ} 19^{\prime} 47.4^{\prime \prime} \mathrm{W}$ ) which is partially separated from the remainder of the woods (and the main study area) by farmlands (Fig. 1). It was not possible to record data blind because our study involved focal animals in the field.

After an initial period (34 days) of acclimation, during which three standard, open-access feeders in this area were provided, they were replaced by six controlled access feeders (see Supplementary Image 1) with a single feeding hole (experimental design described further in Firth and Sheldon (2015) and Firth et al. (2015, 2016)). The 
Fig. 1 Map displaying Wytham Woods; the inset displays Bean Wood and the locations of the feeders used (original feeder sites marked by an $\mathrm{x}$ ). The sizes of the circles represent the relative numbers of individuals that visited, while the colors represent the proportion of male (darker shade) and female (lighter shade) blue tit (blue) and great tit (brown) feeder visits

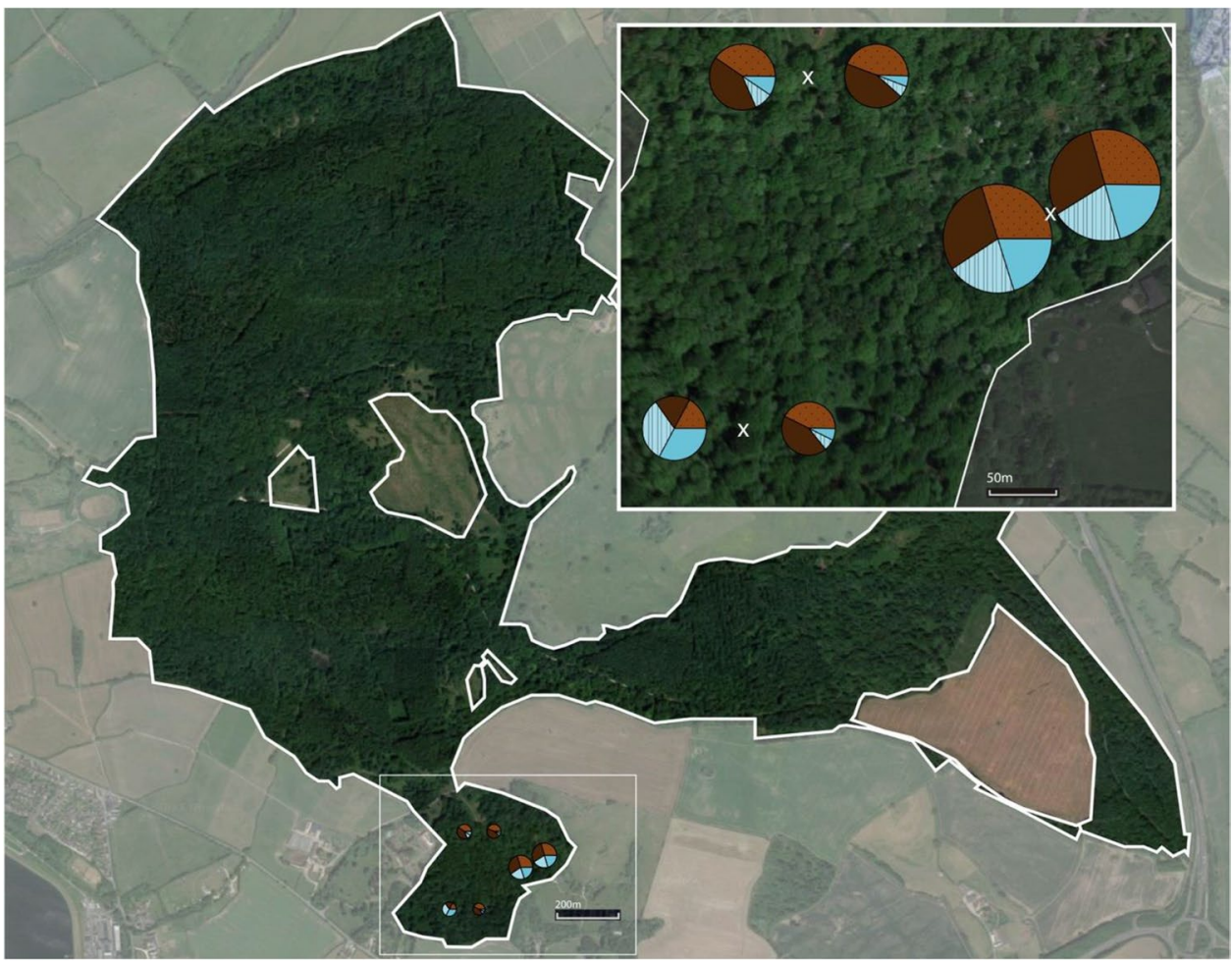

access hole of each feeder was blocked by a transparent flap locked into place; the feeder was unlocked when a PIT tag was registered by the RFID antenna. Once opened, the flap stayed open and unlocked for $2 \mathrm{~s}$. These feeders were used as opposed to normal (open access) RFID-detecting feeders because only tagged birds can initially open the flap. When using open-access feeders (without flap), untagged birds may be regularly feeding at the sites; calculating leading and following based on this open-access data-stream carries the potential of mis-labeling individuals that arrived with untagged birds.

Here, we use two selective feeders placed approximately $100 \mathrm{~m}$ apart at each site (each $50 \mathrm{~m}$ away from the initial standard feeder location). All six feeders were identical and afforded the same opportunities in terms of (1) type and quality of food available and (2) space to access the food from. The selective feeders were open from pre-dawn until after dusk every day. During an initial 34-day acclimation period (30 November to 2 January), the controlled access feeding mechanism was introduced to give PIT-tagged individuals time to learn how to use the selective feeders, i.e., only birds with a tag could visit these feeders. Additionally, this period would discourage untagged individuals from visiting these feeders. Then, once they learned to use the selective feeders, the behavior of the birds was recorded for 16 complete days (3 January to 18 January); any bird with a PIT-tag could unlock the feeders (i.e., same exact procedure as in the acclimation period). Throughout both periods, each feeder visit by a PIT-tagged bird was recorded with the individual's ID as well as the date, time, and location of their visit.

\section{Determining leading and following behavior}

When an individual arrived at a feeder, they had to unlock the flap if another bird had not already done so. Once unlocked, the flap stayed open for $2 \mathrm{~s}$. Initially unlocking the flap came with an associated cost, as the unlocking individual had to wait $<2 \mathrm{~s}$ for the flap to open (the time it takes for the feeder to register the tag and initiate the opening mechanism), making it more likely that there could be interference while they were feeding. On the other hand, those who arrived within the next $2 \mathrm{~s}$ could retrieve food and leave instantly with a smaller risk of others becoming involved or preventing them from feeding. This period of $2 \mathrm{~s}$ is also relevant when we look at the distribution of visit intervals over the course of the test period, with a majority of visits being within 1 or $2 \mathrm{~s}$ of one another (Fig. 2).

Using the spatio-temporal data stream produced by the recorded feeder visits, we labeled each feeder visit as a "lead" or not, according to the following logic and criteria. First, we calculated a leading time (the number of seconds that passed until another PIT-tagged individual visited that feeder) and following time (the number of seconds that passed since the previous PIT-tagged individual visited) for each visit. Based on the distribution of inter-visit intervals and the fact that the flap stayed open for $2 \mathrm{~s}$ upon being unlocked, we defined a feeder visit as a lead if no PIT-tagged 


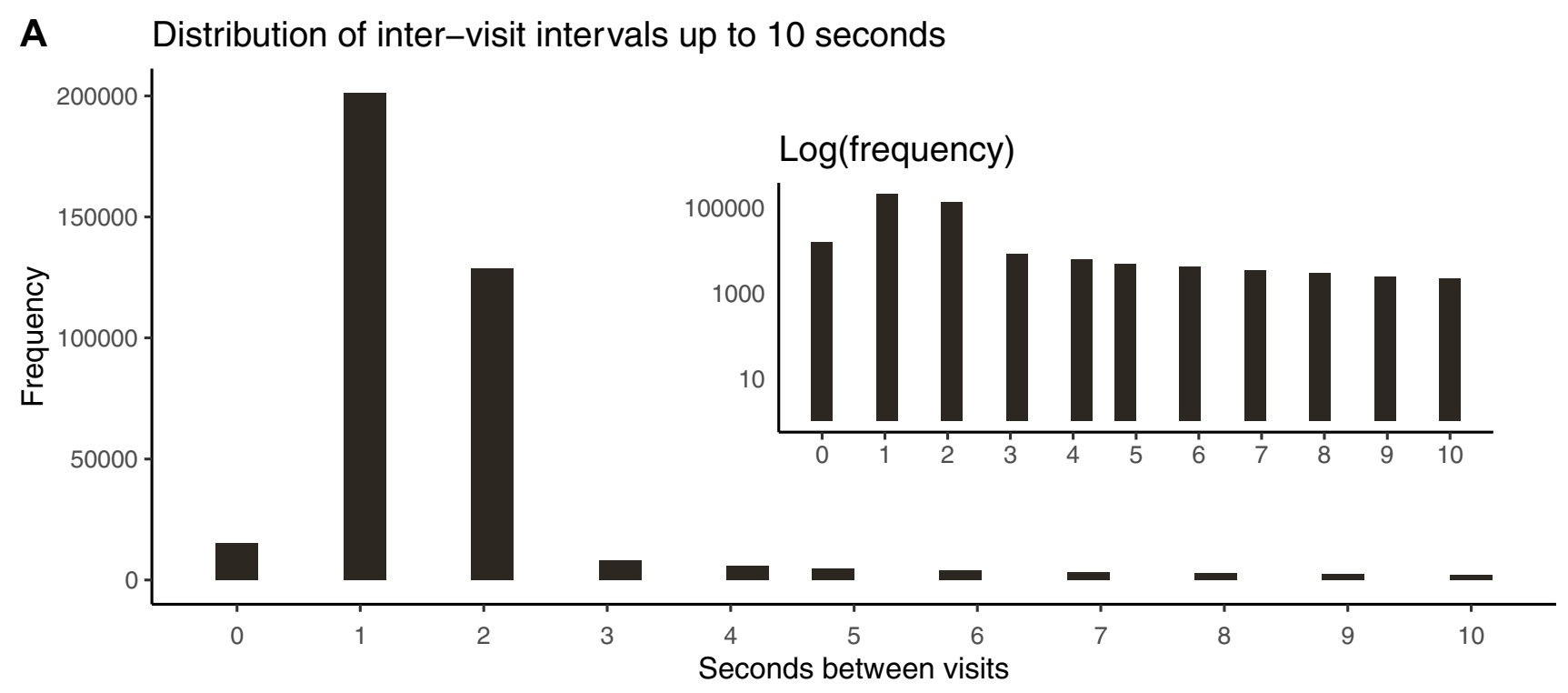

B Distribution of inter-visit intervals up to 10 minutes

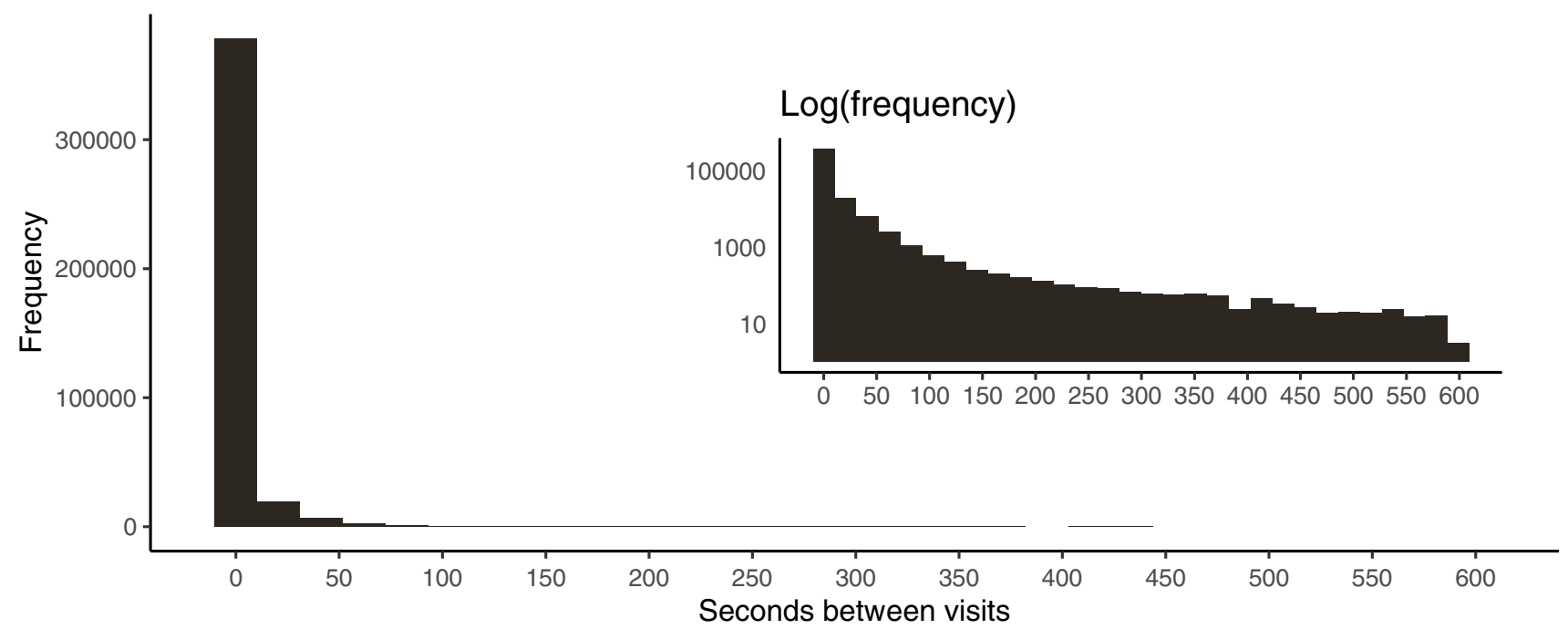

Fig. 2 Panels A and B display the distribution of inter-visit intervals up to $10 \mathrm{~s}$ and $10 \mathrm{~min}$, respectively, over the entire test period; inset plots show the same distribution with the $y$-axis (frequency) on a log scale

birds had arrived within the previous $2 \mathrm{~s} \mathrm{(}>2 \mathrm{~s}$ following time), and a PIT-tagged bird had arrived within the following $2 \mathrm{~s}$ ( $\leq 2 \mathrm{~s}$ leading time; illustrated in Fig. 3 ).

In this way, we capture those feeder visits where a bird is a "leader" and is not following another bird. This variable was used for all of the following analyses. A feeder visit was defined as a "follow" if the focal individual arrived within $2 \mathrm{~s}$ of another PIT-tagged bird ( $\leq 2 \mathrm{~s}$ following time), regardless of whether or not the prior bird was labeled as a leader or follower. To assess leading in an alternative way, we calculated a leading to following ratio (described further in Supplementary Material Sect. 1). We additionally calculated four stricter leadership measures for supplementary analysis where no individual preceded the focal individual's arrival, within $5,10,20$, or $30 \mathrm{~s}$ (e.g., $\leq 5, \leq 10, \leq 20, \leq 30$ following time; Supplementary Material Sect. 2). Rather than focusing on the more relevant cut off of $2 \mathrm{~s}$ (the target of manipulation), these supplementary measures capture a slightly different behavior but still demonstrate fine-scaled within-species differences.

Overall, leaders are individuals that take on the initial cost of the slight time delay $(<2 \mathrm{~s})$ of unlocking the feeders along with any risk associated with being the first individual to approach a feeder/area while others are not there using it. Followers are individuals that arrive immediately after leaders and, therefore, do not have to unlock the feeders themselves and also do not experience any risk associated with being first. This method of labeling leaders and followers 


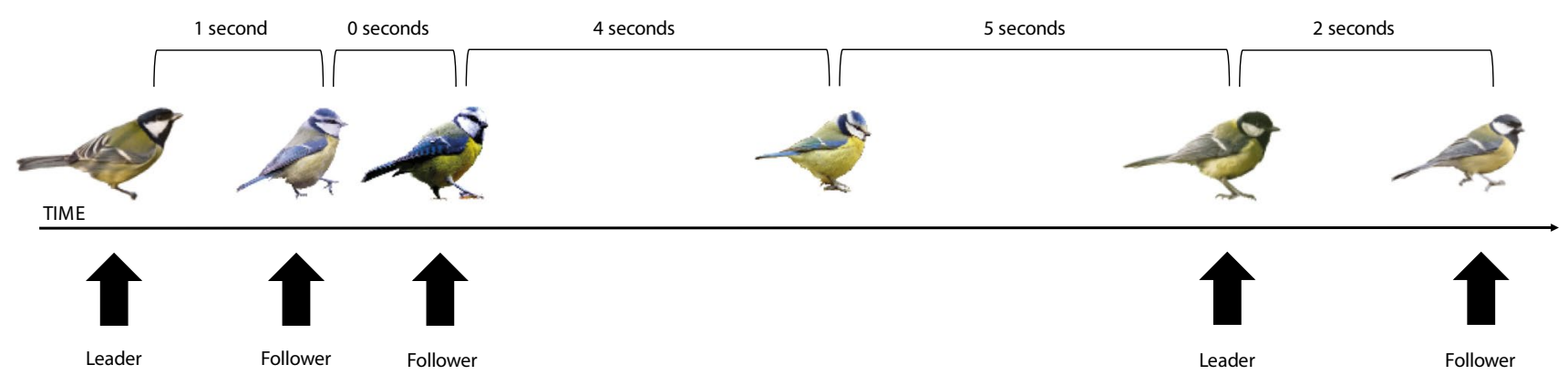

Fig. 3 A visual representation of how leads and follows were determined. Starting from the left (earliest in time), the first bird is classed as a leader, as a bird arrives $<2 \mathrm{~s}$ after, but no bird arrives before them. The second bird is a follower, but not a leader because a bird arrived $<2 \mathrm{~s}$ before them. The third bird is a follower because they arrive $<2 \mathrm{~s}$ after another bird, but no bird arrives $<2 \mathrm{~s}$ after

assumes that the presence of some untagged birds does not significantly change our estimation of leading/following events. We believe this is true as (a) the acclimation period deters untagged birds from using the feeders (as they cannot use any of the feeders directly) and (b) as the "following" window uses such a short time cut-off, the birds which are classed as "followers" are likely to not have been preceded by an untagged individual, and-even in the rare occasions when they were-they are still carrying out the following activity (albeit just coming after a different individual).

\section{Statistical analyses}

To analyze whether leading in this context was associated with factors related to motivation and dominance that we had hypothesized as predictors of leading behavior, binomial generalized linear mixed models (GLMM) were run in R using the package "Ime4." These models were run with the dependent variable of "lead or not," based on each individual feeder visit. We explored various fixed effects and their interactions (age and species and sex and species; detailed in Supplementary Material Tables S8, S9). In all the models, date, location (i.e., feeder), and individual ID were them. The fourth bird is not a leader or follower, because no birds arrive within $<2 \mathrm{~s}$ of them (before or after). The fifth bird is a leader, because they do not follow anyone themselves (i.e., does not arrive $<2 \mathrm{~s}$ after another bird), but the sixth bird arrives $<2 \mathrm{~s}$ after they do (making the final bird a follower)

included as random effects. In the final model (Table 1), species (great tit or blue tit), age (juvenile or adult), sex, and activity (total number of feeder visits in test period) were included as fixed effects. The model was checked using several model diagnostics and visual inspection of residuals (with the "DHARMa" package); none were indicative of any deviations from the assumptions of normality and homogeneity of residuals.

In these primary models, all records for great tits and blue tits are included. However, some individuals were leading and following at similar rates. To perform supplementary sensitivity analysis, we asked whether the same patterns would hold if we removed those individuals in the central part of the distribution and only focused on individuals that are consistently leading or consistently following. In other words, we remove those individuals that are leading and following at similar rates and therefore do not have a strong propensity/preference to be a leader or follower. We first calculated the total number of leads and total number of follows that each individual engaged in to come up with a leading proportion $($ mean $=0.54, \min =0, \max =0.86$, median $=0.60, \mathrm{SD}=0.23$ ). We then calculated the first and fourth quartile of the leading proportion and labeled
Table 1 Binomial GLMM model summary of the observed results with the dependent variable set as lead or not lead, analyzing if each feeder visit is a lead or not

\begin{tabular}{llllr}
\hline Dependent variable & Fixed factor/effects & Estimate \pm SE & $z$ & $p$ \\
\hline Lead or not $N=314,809$ & Intercept & $0.087 \pm 0.129$ & 0.673 & 0.501 \\
& Species (blue tit vs. great tit) & $-0.350 \pm 0.054$ & -6.416 & $<0.001$ \\
& Age (juvenile vs. adult) & $0.065 \pm 0.051$ & 1.262 & 0.207 \\
& Sex (male vs. female) & $0.132 \pm 0.050$ & 2.616 & 0.009 \\
& Activity & $0.168 \pm 0.029$ & 5.846 & $<0.001$ \\
& Random effects & Variance & Standard deviation & \\
& Ring (ID; $N=169)$ & 0.087 & 0.295 & \\
& Date $(N=16)$ & 0.008 & 0.088 & \\
& Feeder (location; $N=6)$ & 0.092 & 0.303 &
\end{tabular}


individuals as having high, middle, or low rates of leads. Records for individuals with "middle" rates of leading (i.e., from the second and third quartiles) were removed from the dataset. We then re-ran the models (Supplementary Material Table S10).

One way to examine the drivers behind various effects is through the use of null models, where the model used for the observed results is re-run numerous times after the response variable is shuffled over chosen spatial and temporal scales (i.e., different restriction types). The observed results are compared to the null model results to separate out predictors that are significantly different from what would be expected by random, i.e., the variable measuring the behavior in question is randomized, but spatial and temporal patterns are retained. Furthermore, because the actions of each individual in a leader-follower pair are somewhat dependent on one another, null models are especially useful for teasing out the patterns that we would expect by chance due to this relationship. To further investigate these results and uncover patterns of non-independence here, null models were run using the "lead or not" model with five different sets of restrictions (Gotelli 2001; Veech 2012). These restrictions keep some characteristics of the data intact while randomizing others, so that we can assess if the observed effects differ from the effects that we would observe by chance (i.e., if birds arrived in a random order). We swapped (randomly re-allocated) the "leading time" and "following time" (the time differences between visits) among individuals (which manipulates the order of arrival) with the following restrictions and ran 10,000 permutations for each restriction type. This swap also ensures that leader-follower pairs are not dependent on one another.

- Site, day, and activity restriction: time differences (leading and following time) are swapped at each feeder on each day. This conserves the spatial and temporal structure of the data, as well as the activity level of each individual.

- Site and activity restriction: time differences are swapped at each feeder. This conserves the activity level of each individual and the spatial but not temporal structure of the data.

- Day and activity restriction: time differences are swapped on each day. This conserves the activity level of each individual and the temporal but not spatial structure of the data.

- Activity restriction only: time differences are swapped with no restriction. Only the activity level of each individual is retained.

- No restrictions: time differences are swapped with no restriction, activity is re-calculated post-swap. The structure of the data is not conserved, effectively allowing for a comparison to what we would expect at random.
$Z$-values for each of the effects in each model were compiled and compared to the observed $z$-value in our real model. The $p$-value was calculated by calculating where the observed value lies within the distribution of values obtained from the null models; results were labeled as "significantly different from expected by the null" if the observed $z$-value was outside of the $95 \%$ range generated by the null models.

\section{Results}

During the 16-day test period, there were a total of 411,158 visits by 128 blue tits (161,496 visits), 71 great tits $(164,148$ visits), 13 marsh tits (68,559 visits), two nuthatches (16,922 visits), and two coal tits (33 visits; see Supplementary Material Table S11 for further details). All following analyses considered great tits and blue tits with known sex only $(N=169$; sex was not known for some birds because they had been ringed as nestlings when sex cannot be reliably determined from visual cues). However, as noted for data on other species, data on individuals of unknown sex were only removed after the labeling of inter-visit intervals and leading-following events ("Determining leading and following behavior" section) was conducted, in order to retain information about the true order of visits and whether they were "following" events.

\section{Observed effects}

Over the test period, species was the strongest predictor of whether a feeder visit was a lead or not with great tits leading more often than blue tits (Table 1, Fig. 4). This is followed closely by activity level, where higher activity is indicative of leading. There was also a much smaller effect of sex (males more likely to be leading). The same patterns are present when considering the leading to following ratio (Table S2). Similar patterns can also be seen at the level of individual feeder visits when records from individuals with similar rates of leading and following ("middle" individuals) are removed from the dataset; however, the effect of sex is no longer significant while the effect of age is larger and significant, suggesting that the sex effect is enhanced by "middle" individuals while the age effect is weakened by "middle" individuals (Supplementary Table S10). When using a stricter definition of leading, only the effect of species remains significant (Table S3-S6).

We additionally ran the same model (from Table 1) for each species separately and with the interaction of sex and age included (Supplementary Material Table S12-S15). For great tits, there is an effect of sex and activity (Table S12), while for blue tits, activity is the only significant predictor (Table S15). For both species, the effect of the interaction 
A
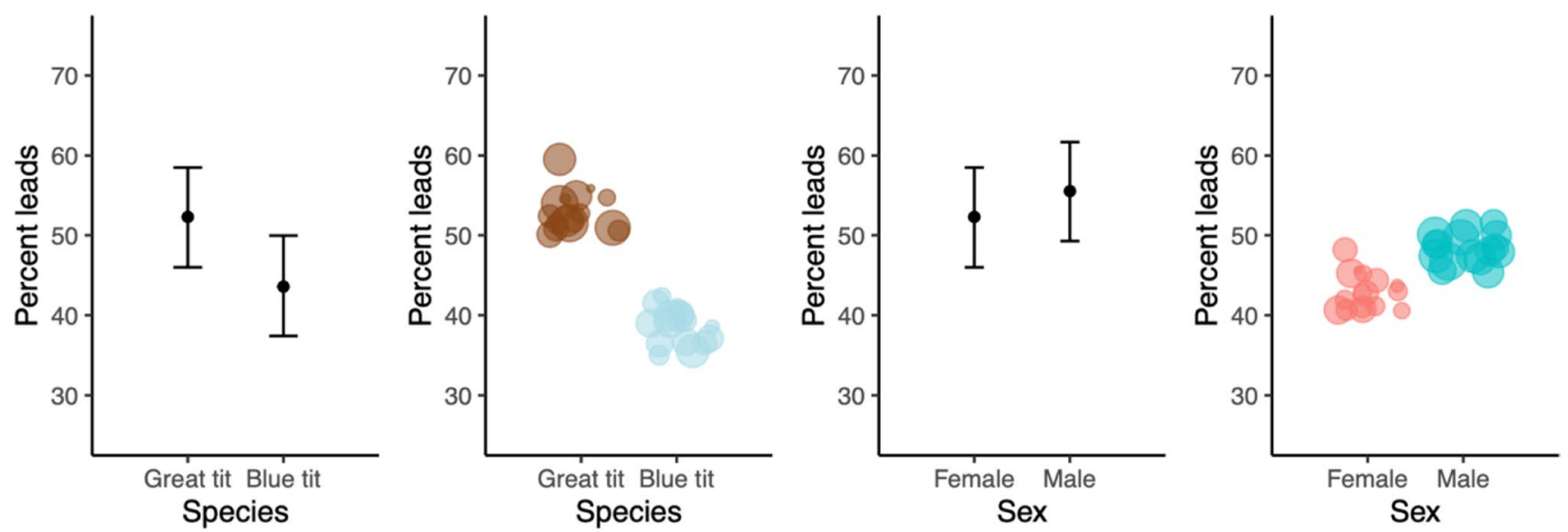

B

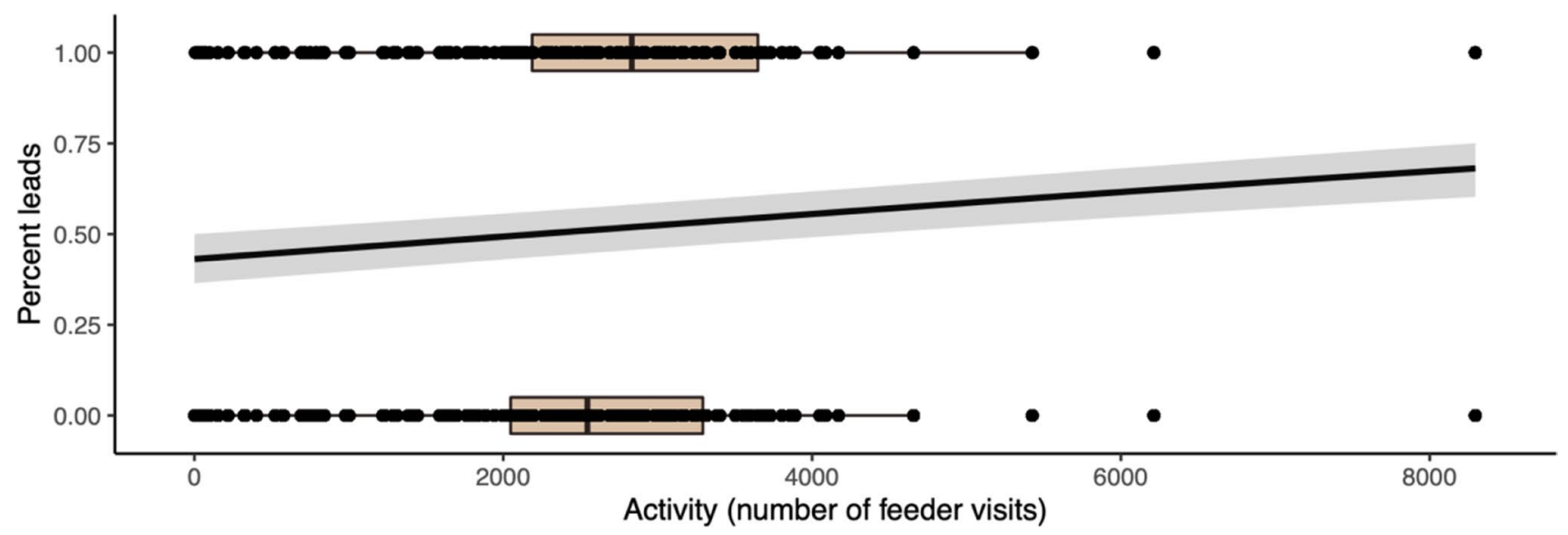

Fig. 4 Plots showing model estimates and raw data for the observed significant $(p<0.01)$ effects of species (panel A, left), sex (panel A, right), and activity (panel $\mathrm{B}$ ) for the model at the level of feeder visits (Table 1). In plot A, black point and error bars represent model estimates and $95 \%$ confidence intervals, while colored points repre-

between age and sex is small and not significant (Table S13, S15).

\section{Null models}

In the most restrictive null model (Fig. 5A), the observed effects of species $\left(\mathrm{p}_{\text {null }}=0.0001\right)$ and age $\left(\mathrm{p}_{\text {null }}=0.0406\right)$ are significantly different than what would be expected if birds were arriving in a random order but still on the same day, at the same feeder, and the same number of times as observed. However, the effects of sex $\left(\mathrm{p}_{\text {null }}=0.9648\right)$ and activity $\left(\mathrm{p}_{\text {null }}=0.1522\right)$ are not, suggesting that these effects in the model are driven by spatial and temporal dynamics. This is also the case when the day restriction is lifted (Fig. 5B); the observed effects of species $\left(\mathrm{p}_{\mathrm{null}}=0.0001\right)$ and age $\left(\mathrm{p}_{\text {null }}=0.0448\right)$ are significantly different than what would be expected if birds were arriving in a random order but at sent the percentage of leads for each day $(N=16)$ in the test period. In plot $\mathrm{B}$, the boxplots and points represent the observed data, while the fitted line and shading show model estimates and 95\% confidence intervals

the same feeder and the same number of times as observed. When the site restriction is lifted instead (date and activity only; Fig. 5C), the observed effect of age $\left(p_{\text {null }}=0.0554\right)$ is on the margin, while species $\left(\mathrm{p}_{\text {null }}=0.0008\right)$ remains significantly different than expected, and sex $\left(\mathrm{p}_{\text {null }}=0.6982\right)$ and activity $\left(\mathrm{p}_{\text {null }}=0.0904\right)$ do not.

In the activity restriction null model (Fig. 5D), only the effect of species $\left(\mathrm{p}_{\text {null }}=0.0006\right)$ is significantly different than what we would expect if birds arrived in a random order, but the same number of times as observed. Again, age is on the margin $\left(\mathrm{p}_{\text {null }}=0.0512\right)$ and sex $\left(\mathrm{p}_{\text {null }}=0.7138\right)$ and activity $\left(p_{\text {null }}=0.0994\right)$ are not different than expected. When there are no restrictions (Fig. 5E), allowing the birds to arrive in a completely random order, all of the observed effects are significantly different than what we would observe by chance, suggesting that the observed effects of age and sex are dependent on activity levels, while the effect of species is not dependent 

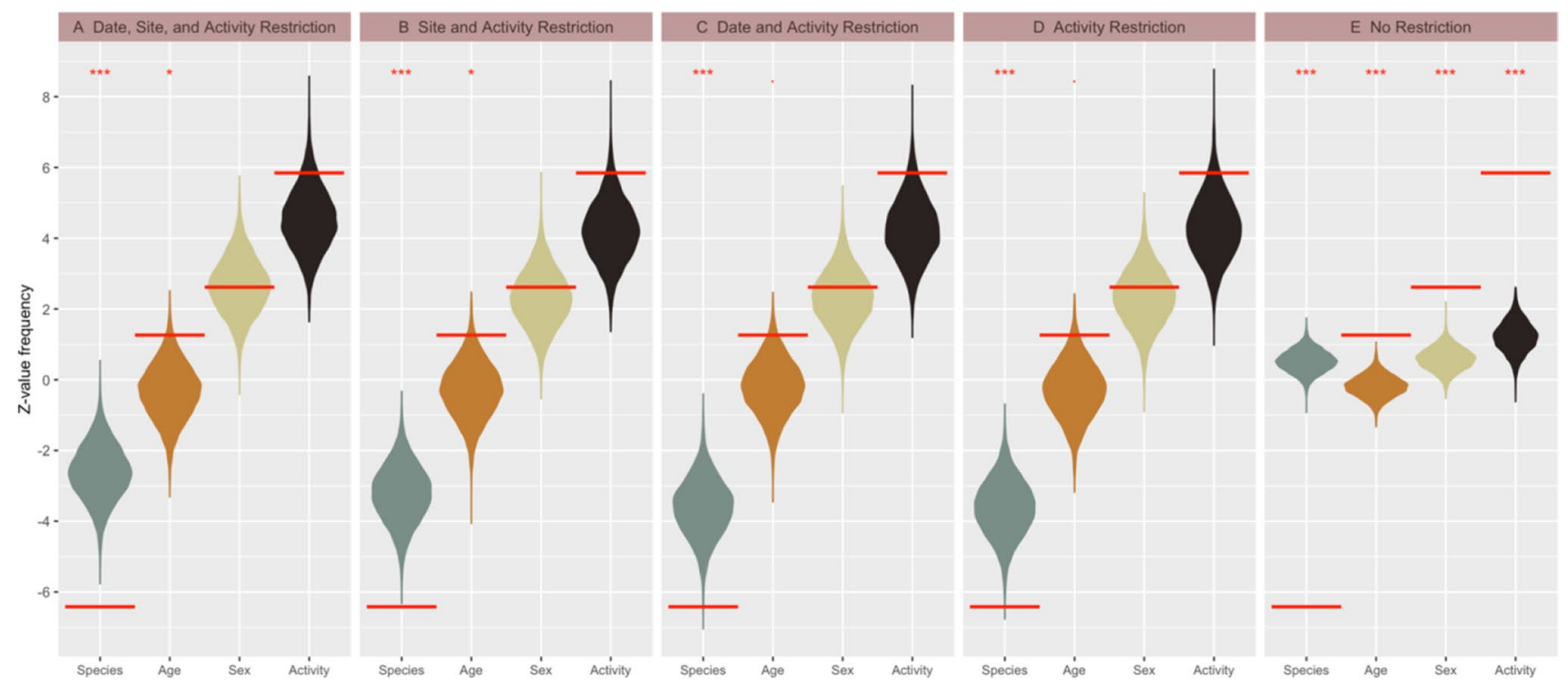

Fig. 5 Violin plots displaying the results of the null models with all five restriction types. Each panel denotes a restriction type, while the fixed effects (of species, age, sex, and activity) are along the $x$-axis. Solid red lines indicate the observed $z$-value for each effect, and the

on any of these restrictive factors. Running the same set of permutations with the great tit only model (Table S12) reveals that the effects of sex and activity are significantly different than what we would observe by chance (no restriction) but not with any of the other restriction types, suggesting that the observed effect of sex within great tits is dependent on where and when birds feed and their activity levels (details in Fig. S1).

\section{Additional following-level species effects}

Having demonstrated a robust effect of species on leading behavior, we further examined the identity of those individuals following great tit vs. blue tit leaders. Of the 164,148 visits by great tits, 86,965 (52.98\%) were leading events. Great tit leaders were followed by blue tits 869 times (1\%), by marsh tits 190 times $(0.22 \%)$, and by nuthatches 37 times $(0.04 \%)$, with the remainder $(85,869,98.74 \%)$ being followed by great tits. Of the 161,496 visits by blue tits, 62,340 (38.60\%) were leading events. Blue tit leaders were followed by great tits 511 times $(0.82 \%)$, by marsh tits 190 times $(0.30 \%)$, by nuthatches 18 times $(0.03 \%)$, and by one coal tit, with the remainder $(61,605,98.82 \%$ of the time $)$ being followed by blue tits.

\section{Discussion}

Patterns of passive leading behavior can be dependent on various characteristics of the individual, and the effects of these characteristics can themselves be driven by spatial and stars at the top of the y-axis denote significance levels, i.e., whether the observed $z$-value is significantly different from those derived from the null models $(* * *=<0.001, *=<0.05,=<0.1)$

temporal dynamics (where and when individuals are feeding). Here, we defined passive leaders as individuals who (1) initially unlocked a feeder, taking on the cost of waiting for feeders to open, and (2) did this more often than they followed others. In wild mixed-species flocks of passerine birds, leading behavior within locations is influenced by species, sex, and activity. As expected, indicators of dominance and motivation appear to shape which individuals arrive at feeders without following others. Overall, great tits lead more often than blue tits. In terms of within-species effects, blue tits with higher activity levels were more likely to be leaders, but there was no significant effect of age or sex. For great tits, males and individuals with higher levels of activity were more likely to be leaders, but both effects are spatio-temporally driven. It is unclear if this is driven solely by these mechanisms or if individuals prefer to feed in particular locations at specific times because they are more (or less) likely to be leaders there. The most robust finding here is that great tits lead more often than blue tits; great tits are more likely to initially unlock a feeder once a group has arrived at a feeding location.

By using null models, we were also able to investigate the mechanics of this leading behavior. The effect of sex and activity is driven by spatial and temporal dynamics (where and when individuals feed), while the effect of species is robust to a wide range of alternative null models (not driven by the time or location of feeding). Additionally, estimates of leading behavior are highly dependent on the total number of feeder visits an individual made (individuals with higher feeder visits have higher estimates of leading 
behavior), suggesting that the number of times an individual is observed may influence results regardless of differences in leading behavior.

The results obtained here emphasize the importance of using null models for understanding the drivers of different processes. Previous studies that identify leading behavior often ascribe effects to individual-level processes when they may have other drivers. Although some effects (like sex and activity here) may be spatio-temporally driven, it is still important to consider them. Is it the case that the effect of sex seems to be driven by temporal and spatial aspects simply because that is what constrains these results, or is it because males and females have different preferences in terms of being a leader and follower in this system? In other words, individuals may be non-random in their choices of where and when to feed. For example, juvenile great tits have been found to have more social connections than adults, and this is driven by spatial dynamics-juveniles visit locations with larger groups or with higher levels of activity (Farine et al. 2015). However, it is still possible that juveniles prefer to be more social and are engaging in feeding at these times and locations for precisely that reason. To test causality in these situations, further experimental evidence is necessary; by manipulating where and when individuals can feed or be, we can look at whether individuals continue to be leaders (or followers) in the absence of the possibility to influence their own spatial and temporal decisions. For example, in the case of this system, if an individual that does not engage in leading often is restricted to a feeder where there are high activity levels, will they begin leading?

In this mixed-species population, dominance is related to body size both within and among species (Morse 1978, p. 300; Gosler and Carruthers 1999). Great tits are the largest and most dominant species in these flocks and regularly succeed over blue tits in competition for nest boxes (Dhondt and Eyckerman 1980; Minot and Perrins 1986; Kempenaers and Dhondt 1991). The fact that great tits are leading more often in this population is in line with existing theories of leading on the basis of dominance and energetic requirements (Rands et al. 2006; Conradt et al. 2009; Öst and Jaatinen 2013). Furthermore, more dominant individuals in this population are more vigilant during foraging, and there is a causal relationship between dominance and competence in choosing the safest foraging locations (Krams 1998), making great tits ideal leaders. What is striking, however, is the fact that great tits and blue tits almost exclusively follow conspecifics. In other words, individuals are unlikely to initially approach a feeder that has been opened by another individual unless that individual is a conspecific. The reason for this is unclear and remains to be tested.

All studies focusing on a particular aspect of leadership are limited to drawing conclusions within that particular context. Indeed, leadership is not absolute, meaning that leading in each instance may depend on the identity of leader-follower pairs even in a passive context. Within this particular study, for example, even though the experimental feeding system allows examination of leadership under natural settings, it is difficult to determine if the activity that occurs here would directly reflect the leader-follower relations that would occur within other foraging conditions (e.g., on natural food sources without centralized feeders) or other differing environmental conditions (Carrascal et al. 1998). Furthermore, it is also important to note that when studying leadership in the context of activity within a particular area (such as done in this study), this may not directly relate to leadership in the context of collective movement between areas (such as is done in many other studies). As such, future work directly testing how leadership carries over across different contexts (e.g., different foraging situations or within- vs. between-area movement) would be of much interest. Finally, the precise costs and benefits of being a leader or follower could not be ascertained in this study. For example, precise monitoring of predation risk is difficult with this set-up (but see Voelkl et al. (2016) for findings on predation dynamics in a separate experiment). Further experimental (in captivity) and observational (in the wild) studies are necessary to uncover and quantify the relative costs of leadership (Ioannou et al. 2019).

There are also other possible factors that may have an influence on leading. Temperament or personality may have an impact; in their study on pairs of sticklebacks (Gasterosteus aculeatus), Harcourt et al. (2009) found that bold individuals were more likely to lead and less likely to follow than shy individuals. Kurvers et al. (2009) go so far as to argue that individual differences in personality may be maintained in order to foster social coordination. Social relationships can also play a role, with individuals following the behaviors of their close social partners (Jacobs et al. 2011). Some studies have even shown that reproductive status may have an impact on leading behavior, most likely due to the energetic requirement that comes with breeding (Pyritz et al. 2011). In some situations that are more movementbased than the passive leadership studied here, having more information or knowledge about how or where the collective action will take place can increase the probability that an individual leads. This is especially the case in joint navigation, where previous experience or knowledge of a route is crucial to success (Flack et al. 2012). Further work is needed to gain a more complete picture of the drivers of leading behavior and how they may operate in different settings.

\section{Conclusion}

Collective behaviors are widespread in the animal kingdom, and discovering which individual initiates them, and which individuals follow initiation, is crucial to our understanding 
of sociality and several social processes (King et al. 2009). Here, we show that there are species differences in passive leading behavior, in a natural population of wild birds, that are in line with theories on leading that are related to motivation in terms of nutritional requirements as well as dominance. Great tits, the larger and more dominant species, are leading more often than blue tits. However, when individuals do lead, they are almost exclusively followed by conspecifics. Furthermore, our use of null models shows that the observed effects of sex (males leading more than females) and activity (higher activity levels associated with more leading) are driven by spatial and temporal dynamics; this highlights the utility of using null models to explore patterns of non-independence and uncover the mechanisms behind various effects. Future work can integrate other proposed predictors of leadership (measures of personality, more precise measures of metabolic rate, social structure, etc.) to gain a more holistic understanding of passive leadership. There would also be much benefit in manipulating spatial and temporal dynamics to provide further insights into how experimental changes impact leading behavior and to allow for concrete conclusions regarding the causes of leading behavior to be drawn.

Supplementary Information The online version contains supplementary material available at https://doi.org/10.1007/s00265-021-03103-3.

Acknowledgements We thank Melanie Ghoul, Christopher Pull, and two anonymous reviewers for their helpful feedback on this work and Ferhat Yesilada and Rahel Katharina Brügger for their help with producing Figs.

Funding This work was supported by BBSRC (BB/S009752/1) and NERC (NE/S010335/1) to JAF and by BBSRC (BB/L006081/1) to BCS.

Data availability The dataset analyzed during the current study is available in the "leadingsongbirds" repository, https://github.com/samin gokcekus/leadingsongbirds.

\section{Declarations}

Ethics approval All work was reviewed and approved by the local ethical review committee (Department of Zoology, University of Oxford, $\mathrm{UK}$ ) and adhered to UK licensing requirements as well as the ASAB/ ABS Guidelines for the Use of Animals in Research. This work was conducted as part of a larger, ongoing research project at Wytham Woods. All birds were caught and ringed by appropriate BTO license holders.

Conflict of interest The authors declare no competing interests.

Open Access This article is licensed under a Creative Commons Attribution 4.0 International License, which permits use, sharing, adaptation, distribution and reproduction in any medium or format, as long as you give appropriate credit to the original author(s) and the source, provide a link to the Creative Commons licence, and indicate if changes were made. The images or other third party material in this article are included in the article's Creative Commons licence, unless indicated otherwise in a credit line to the material. If material is not included in the article's Creative Commons licence and your intended use is not permitted by statutory regulation or exceeds the permitted use, you will need to obtain permission directly from the copyright holder. To view a copy of this licence, visit http://creativecommons.org/licenses/by/4.0/.

\section{References}

Aplin LM, Farine DR, Morand-Ferron J, Cole EF, Cockburn A, Sheldon BC (2013) Individual personalities predict social behaviour in wild networks of great tits (Parus major). Ecol Lett 16:1365-1372. https://doi.org/10.1111/ele.12181

Beauchamp G (2000) Individual differences in activity and exploration influence leadership in pairs of foraging zebra finches. Behaviour 137:301-314. https://doi.org/10.1163/1568539005 02097

Carrascal LM, Senar JC, Mozetich I (1998) Interactions among environmental stress, body condition, nutritional status, and dominance in great tits. Auk 115:727-738. https://doi.org/10.2307/ 4089420

Clark CW, Mangel M (1986) The evolutionary advantages of group foraging. Theor Popul Biol 30:45-75. https://doi.org/10.1016/ 0040-5809(86)90024-9

Conradt L, Krause J, Couzin ID, Roper TJ (2009) "Leading according to need" in self-organizing groups. Am Nat 173:304-312. https:// doi.org/10.1086/596532

Conradt L, Roper TJ (2003) Group decision-making in animals. Nature 421:155-158

Couzin ID, Krause J (2003) Self-organization and collective behavior in vertebrates. Adv Stud Behav 32:1-75. https://doi.org/10.1016/ S0065-3454(03)01001-5

Couzin ID, Krause J, James R, Ruxton GD, Franks NR (2002) Collective memory and spatial sorting in animal groups. J Theor Biol 218:1-11. https://doi.org/10.1006/jtbi.2002.3065

Dhondt AA, Eyckerman R (1980) Competition between the Great tit and the Blue tit outside the breeding season in field experiments. Ecology 61:1291-1296

Dumont B, Boissy A, Achard C, Sibbald AM, Erhard HW (2005) Consistency of animal order in spontaneous group movements allows the measurement of leadership in a group of grazing heifers. Appl Anim Behav Sci 95:55-66. https://doi.org/10.1016/j. applanim.2005.04.005

Farine DR, Firth JA, Aplin LM et al (2015) The role of social and ecological processes in structuring animal populations: a case study from automated tracking of wild birds. R Soc Open Sci 2:150057. https://doi.org/10.1098/rsos.150057

Farine DR, Garroway CJ, Sheldon BC (2012) Social network analysis of mixed-species flocks: exploring the structure and evolution of interspecific social behaviour. Anim Behav 84:1271-1277. https:// doi.org/10.1016/j.anbehav.2012.08.008

Firth JA, Sheldon BC (2015) Experimental manipulation of avian social structure reveals segregation is carried over across contexts. Proc R Soc B 282:20142350. https://doi.org/10.1098/rspb. 2014.2350

Firth JA, Sheldon BC, Farine DR (2016) Pathways of information transmission among wild songbirds follow experimentally imposed changes in social foraging structure. Biol Lett 12:20160144. https://doi.org/10.1098/rsbl.2016.0144

Firth JA, Voelkl B, Farine DR, Sheldon BC (2015) Experimental evidence that social relationships determine individual foraging behavior. Curr Biol 25:3138-3143. https://doi.org/10.1016/j.cub. 2015.09.075 
Flack A, Pettit B, Freeman R, Guilford T, Biro D (2012) What are leaders made of? The role of individual experience in determining leader-follower relations in homing pigeons. Anim Behav 83:703-709. https://doi.org/10.1016/j.anbehav.2011.12.018

Furrer RD, Kunc HP, Manser MB (2012) Variable initiators of group departure in a cooperative breeder: the influence of sex, age, state and foraging success. Anim Behav 84:205-212. https://doi.org/ 10.1016/j.anbehav.2012.04.034

Gibb J (1954) Feeding ecology of tits, with notes on treecreeper and goldcrest. Ibis 96:513-543. https://doi.org/10.1111/j.1474-919X. 1954.tb05476.x

Gosler A, Carruthers T (1999) Body reserves and social dominance in the Great tit Parus major in relation to winter weather in southwest Ireland. J Avian Biol 30:447-459

Gotelli NJ (2001) Research frontiers in null model analysis. Glob Ecol Biogeogr 10:337-343. https://doi.org/10.1046/j.1466822X.2001.00249.x

Griggio M, Serra L, Licheri D, Monti A, Pilastro A (2007) Armaments and ornaments in the rock sparrow: a possible dual utility of a carotenoid-based feather signal. Behav Ecol Sociobiol 61:423-433. https://doi.org/10.1007/s00265-006-0270-5

Hansen MJ, Schaerf TM, Krause J, Ward AJW (2016) Crimson spotted rainbowfish (Melanotaenia duboulayi) change their spatial position according to nutritional requirement. PLoS ONE 11:e0148334. https://doi.org/10.1371/journal.pone. 0148334

Harcourt JL, Ang TZ, Sweetman G, Johnstone R, Manica A (2009) Social feedback and the emergence of leaders and followers. Curr Biol 19:248-252. https://doi.org/10.1016/j.cub.2008.12. 051

Hinde RA (1952) The behaviour of the great tit (Parus major) and some other related species. Behaviour Suppl 2:1-201

Ioannou CC, Rocque F, Herbert-Read JE, Duffield C, Firth JA (2019) Predators attacking virtual prey reveal the costs and benefits of leadership. P Natl Acad Sci USA 116:8925-8930. https://doi. org/10.1073/pnas.1816323116

Jacobs A, Sueur C, Deneubourg JL, Petit O (2011) Social network influences decision making during collective movements in brown lemurs (Eulemur fulvus fulvus). Int J Primatol 32:721736. https://doi.org/10.1007/s10764-011-9497-8

Kasumovic MM, Bruce MJ, Andrade MCB, Herberstein ME (2008) Spatial and temporal demographic variation drives within-season fluctuations in sexual selection. Evolution 62:2316-2325. https://doi.org/10.1111/j.1558-5646.2008.00446.x

Kay SL, Fischer JW, Monaghan AJ et al (2017) Quantifying drivers of wild pig movement across multiple spatial and temporal scales. Mov Ecol 5:14. https://doi.org/10.1186/ s40462-017-0105-1

Kempenaers B, Dhondt AA (1991) Competition between blue and great tit for roosting sites in winter: an aviary experiment. Ornis Scand 22:73-75. https://doi.org/10.2307/3676624

Kern JM, Radford AN (2018) Experimental evidence for delayed contingent cooperation among wild dwarf mongooses. P Natl Acad Sci USA 115:6255-6260. https://doi.org/10.1073/pnas. 1801000115

King AJ (2010) Follow me! I'm a leader if you do; I'm a failed initiator if you don't? Behav Process 84:671-674. https://doi.org/10. 1016/j.beproc.2010.03.006

King AJ, Cowlishaw G (2009) Leaders, followers and group decision-making. Commun Integr Biol 2:147-150. https://doi.org/ 10.4161/cib.7562

King AJ, Douglas CMS, Huchard E, Isaac NJB, Cowlishaw G (2008) Dominance and affiliation mediate despotism in a social primate. Curr Biol 18:1833-1838. https://doi.org/10.1016/j.cub. 2008.10.048
King AJ, Johnson DDP, Van Vugt M (2009) The origins and evolution of leadership. Curr Biol 19:R911-R916. https://doi.org/10. 1016/j.cub.2009.07.027

King AJ, Sueur C (2011) Where next? Group coordination and collective decision making by primates. Int J Primatol 32:12451267. https://doi.org/10.1007/s10764-011-9526-7

Krams I (1998) Dominance-specific vigilance in the great tit. J Avian Biol 29:55-60

Krause J, Ruxton GD (2002) Living in groups. Oxford University Press, New York

Kurvers RHJM, Eijkelenkamp B, van Oers K, van Lith B, van Wieren SE, Ydenberg RC, Prins HHT (2009) Personality differences explain leadership in barnacle geese. Anim Behav 78:447-453. https://doi.org/10.1016/j.anbehav.2009.06.002

Lucon-Xiccato T, Anastasia N, Mazzoldi C, Griggio M (2019) Familiarity and sex modulate size-dependent following behaviour in the Mediterranean killifish. Sci Nat 106:31. https://doi. org/10.1007/s00114-019-1630-0

McClure M, Ralph M, Despland E (2011) Group leadership depends on energetic state in a nomadic collective foraging caterpillar. Behav Ecol Sociobiol 65:1573-1579. https://doi.org/10.1007/ s00265-011-1167-5

Methion S, Díaz López B (2020) Individual foraging variation drives social organization in bottlenose dolphins. Behav Ecol 31:97106. https://doi.org/10.1093/beheco/arz160

Milligan ND, Radersma R, Cole EF, Sheldon BC (2017) To graze or gorge: consistency and flexibility of individual foraging tactics in tits. J Anim Ecol 86:826-836. https://doi.org/10.1111/ 1365-2656.12651

Minot EO, Perrins CM (1986) Interspecific interference competition-Nest sites for blue and great tits. J Anim Ecol 55:331-350

Morse H (1978) Structure and foraging patterns of flocks of tits and associated species in an English woodland during the winter. Ibis 120:298-312

Muller MN, Wrangham RW (2004) Dominance, cortisol and stress in wild chimpanzees (Pan troglodytes schweinfurthii). Behav Ecol Sociobiol 55:332-340. https://doi.org/10.1007/ s00265-003-0713-1

Öst M, Jaatinen K (2013) Relative importance of social status and physiological need in determining leadership in a social forager. PLoS ONE 8:e64778. https://doi.org/10.1371/journal. pone. 0064778

Pyritz LW, Kappeler PM, Fichtel C (2011) Coordination of group movements in wild red-fronted lemurs (Eulemur rufifrons): processes and influence of ecological and reproductive seasonality. Int J Primatol 32:1325-1347. https://doi.org/10.1007/ s10764-011-9549-0

Rands SA, Cowlishaw G, Pettifor RA, Rowcliffe JM, Johnstone RA (2003) Spontaneous emergence of leaders and followers in foraging pairs. Nature 423:432-434. https://doi.org/10.1038/natur $\mathrm{e} 01630$

Rands SA, Pettifor RA, Rowcliffe JM, Cowlishaw G (2006) Social foraging and dominance relationships: the effects of socially mediated interference. Behav Ecol Sociobiol 60:572-581. https://doi.org/10.1007/s00265-006-0202-4

Réale D, Garant D, Humphries MM, Bergeron P, Careau V, Montiglio PO (2010) Personality and the emergence of the paceof-life syndrome concept at the population level. Phil Trans R Soc B 365:4051-4063. https://doi.org/10.1098/rstb.2010.0208

Stephens DW, Brown JS, Ydenberg RC (2007) Foraging: behavior and ecology. University of Chicago Press, Chicago

Strandburg-Peshkin A, Papageorgiou D, Crofoot MC, Farine DR (2018) Inferring influence and leadership in moving animal groups. Phil Trans R Soc B 373:20170006. https://doi.org/10. 1098/rstb.2017.0006 
Sueur C, MacIntosh AJJ, Jacobs AT, Watanabe K, Petit O (2013) Predicting leadership using nutrient requirements and dominance rank of group members. Behav Ecol Sociobiol 67:457470. https://doi.org/10.1007/s00265-012-1466-5

Sumpter DJT (2009) Group behaviour: leadership by those in need. Curr Biol 19:R325-R327. https://doi.org/10.1016/j.cub.2009. 02.049

Tóth Z, Griggio M (2011) Leaders are more attractive: birds with bigger yellow breast patches are followed by more group-mates in foraging groups. PLoS ONE 6:e26605. https://doi.org/10. 1371/journal.pone.0026605

Veech JA (2012) Significance testing in ecological null models. Theor Ecol 5:611-616. https://doi.org/10.1007/s12080-012-0159-z
Voelkl B, Firth JA, Sheldon BC (2016) Nonlethal predator effects on the turn-over of wild bird flocks. Sci Rep 6:33476. https://doi. org/10.1038/srep33476

Voelkl B, Portugal SJ, Unsölde M, Usherwood JR, Wilsond AM, Fritz J (2015) Matching times of leading and following suggest cooperation through direct reciprocity during V-formation flight in ibis. P Natl Acad Sci USA 112:2115-2120. https://doi.org/ $10.1073 /$ pnas. 1413589112

Publisher's Note Springer Nature remains neutral with regard to jurisdictional claims in published maps and institutional affiliations. 